\title{
Eastern asian expert panel opinion: designing clinical trials of molecular targeted therapy for hepatocellular carcinoma
}

\author{
Winnie Yeo ${ }^{1 *}$, Pei-Jer Chen², Junji Furuse ${ }^{3}$, Kwang-Hyub Han ${ }^{4}$ Chiun Hsu², Ho-Yeong Lim ${ }^{5}$, Hanlim Moon \\ Shukui Qin", Ee-Min Yeoh ${ }^{6}$, Sheng-Long Ye ${ }^{8}$
}

\begin{abstract}
The largest burden of hepatocellular carcinoma (HCC) lies in Asia, secondary to hepatitis B virus (HBV) infection. Improved survival with sorafenib has fostered new research but many challenges remain in designing clinical trials. The disease, its management, and populations affected by it are heterogeneous worldwide and within Asia. An expert conference of Eastern Asian oncologists and hepatologists was convened to foster consensus in clinical trial design. The panel identified key areas that need to be addressed to facilitate clinical trials in Asia. Stratification by viral etiology is desirable within Asia and by region in global trials. Antiviral therapy should also be considered as a stratification factor and incorporated into HCC management in trials. The panel agreed that histological diagnosis is not required for trial entry and that Barcelona-Clinic Liver Cancer (BCLC) staging is acceptable for trials as long as portal hypertension can be better defined with standardized methodology. Consensus in treatment must be sought to allow multi-national trials and it must be recognized that first-line sorafenib is not largely feasible in Asia. Finally, Asian nations must be urged to participate in clinical trials, many of which are ongoing, to advance new treatment options in this challenging disease.
\end{abstract}

\section{Background}

Over 600,000 cases of hepatocellular carcinoma (HCC) are diagnosed annually worldwide and the mortality-toincidence rate ratio is second only to pancreatic cancer $[1,2]$. The incidence of HCC varies widely by geographical region. Asia carries the largest burden with $55 \%$ of all cases occurring in China [1]. Age-standardized incidence rates per 100,000 persons for men are 45.0 in Korea (1999-2001) [3], 37.9 in China (2002) [1], and 23.1 in Japan (2002) [1]. Corresponding rates for women are 12.0, 14.2, and 7.6. Globally, the predominant cause of HCC is viral infection with hepatitis B virus (HBV) or hepatitis $\mathrm{C}$ virus (HCV) [4].

Hepatocellular carcinoma is refractory to cytotoxic chemotherapy [5] and the failure of cytotoxic regimens has led to a bleak outlook. However, the recent development of molecular targeted therapies is changing the landscape and offering hope. Researchers have found

\footnotetext{
* Correspondence: winnie@clo.cuhk.edu.hk

'Prince of Wales Hospital, Shatin, Hong Kong

Full list of author information is available at the end of the article
}

new optimism for initiating clinical trials after sorafenib showed efficacy in advanced disease [6]. Currently, trials are planned or ongoing in all stages of HCC; however, many issues remain [7]. Most salient is the variability in management practices both between Asia and the West and within Asia. Key differences are apparent in the etiology, diagnosis, staging, and treatment of HCC among countries. These differences complicate the conduct of international clinical trials that will foster approval and availability of new therapeutic entities.

In order to forge a better understanding of how HCC clinical practices in the Eastern Asian region compare to current global clinical trial requirements, an expert conference was held. Participants of the panel (the authors) are oncologists and hepatologists representing China, Hong Kong, Japan, Korea, and Taiwan who have an expertise in treating HCC. Each panelist offered insight, reviewed herein, about how HCC is managed across Eastern Asia and how management practices and clinical trial requirements can be unified to advance new treatments, particularly targeted agents, for HCC. 


\section{Etiology}

Viral etiology varies by region with HBV predominating in non-Japanese Asians and accounting for approximately $70-80 \%$ of cases. In Japan, most of Europe, and in the United States, HCV is more common than HBV among viral etiologies [3,8-11]. However, in the United States, $67 \%$ of HCC cases are seronegative for both viruses [10].

The increased incidence of HBV-HCC in Eastern Asia compared to Japan and Western nations leads to different management issues and prognosis that affect clinical trial design. Hepatitis $\mathrm{C}$ virus-HCC is more likely to develop in the background of cirrhosis than HBV-HCC [12]. Therefore, the underlying liver disease may differ in HCC patients by region, a factor that weighs heavily in treatment decisions.

Survival differences have been observed according to geographic region and viral etiology, though the reasons for these observations remain unclear. In clinical trials of systemic therapy for advanced HCC, trials done in Asian countries reported inferior survival compared with trials done in non-Asian countries [13]. Possible reasons include variation in genetic and/or epigenetic aberrations between different viral etiologies and the propensity for Asian physicians to use local therapy more aggressively and in later stages, resulting in enrollment of a more advanced patient population to trials of systemic therapy. Survival between HBV-HCC and $\mathrm{HCV}-\mathrm{HCC}$ appears similar in early-stage, resectable $\mathrm{HCC}$, if staging and other clinical parameters are considered [14]. However, two retrospective studies have found poorer survival in $\mathrm{HBV}-\mathrm{HCC}$ among patients with unresectable, advanced disease $[15,16]$. Attributing the survival difference to viral etiology alone is difficult but demonstrates the need for considering the potential differences in clinical trials.

Additionally, in contrast to $\mathrm{HCV}, \mathrm{HBV}$ reactivates with immune suppression, complicating treatment with immunosuppressive regimens $[17,18]$. The predominance of HBV-HCC in Asia is associated with increased use of antiviral agents to prevent viral reactivation during $\mathrm{HCC}$ treatment. Antiviral therapy with lamivudine has reduced the incidences of $\mathrm{HBV}$ reactivation and hepatitis, reduced the severity of hepatitis episodes, led to fewer disruptions in chemotherapy, and reduced mortality related to $\mathrm{HBV}$ reactivation in clinical trials of patients with $\mathrm{HCC}$ or other cancers who are receiving chemotherapy [19-22]. Anti-viral therapy following curative resection, radiofrequency ablation, or other local, non-chemotherapeutic treatments for HBV-HCC, has been shown to increase residual liver volume and/or function and may prolong survival [23-25]. Furthermore, interferon, given after curative therapy, may increase recurrence-free survival rates [26,27]. These benefits indicate that use of antiviral therapy is an important confounding factor in HCC clinical trials.

A separate international expert panel has recommended stratification according to region for global trials but discouraged further stratification according to etiology [7]. However, in light of the confounding factors described herein, the current panel agreed that trials within Eastern Asia should include stratification by HBV or HCV etiology. Further, antiviral therapy should be both considered as a stratification factor and incorporated into the overall management of patients in international HCC clinical trials.

\section{Screening}

Stage at diagnosis differs both within Eastern Asia and between Eastern Asia and Western nations. Using TNM-based staging systems, China and Japan have relatively high proportion of patients diagnosed at Stage I or II compared to Hong Kong and Korea. In the United States, a higher percentage of patients are diagnosed with distant metastasis compared to Asian countries [28,29].

The differences may reflect variable screening practices. The proportion of patients who receive screening in the United States appears to vary according to the individual's healthcare. Only $25 \%$ of family practice physicians report routinely screening appropriate patients for HCC compared to $84 \%$ of physicians who are members of the Association for the Study of Liver Diseases (AASLD) [30,31]. In a study of 157 patients diagnosed with HCC at three US Veteran Affairs (VA) medical centers, 39\% of patients with a known risk factor for HCC received screening [32]. With the exception of Hong Kong, where screening has been conducted in the context of study, screening high-risk populations is the standard of care in Asia. With diagnosis occurring at earlier stages, Eastern Asian countries are better able to utilize curative therapies, significantly affecting treatment paradigms and clinical trial populations.

\section{Diagnosis}

Both pathological and clinical diagnostic procedures vary according to country. The majority of pathological diagnoses are made by core biopsy in Korea, China, and Hong Kong, with fine needle aspiration (FNA) used infrequently. In contrast, $30 \%$ or fewer of pathological diagnoses are made by core biopsy in Japan, and Taiwan. Taiwan employs FNA in approximately $10 \%$ of cases but utilizes surgery for pathologic diagnosis in approximately $38 \%$ of cases. Protocols designating biopsy-proven $\mathrm{HCC}$ as an enrollment requirement would conflict with current practices in Japan and 
Taiwan. The panel agreed that for trials conducted in the advanced/metastatic setting, histological confirmation of HCC is not necessary. Further, pre-treatment biopsy may result in tumor seeding which would complicate neoadjuvant trials.

\section{Staging}

A variety of staging systems are employed worldwide [33-36]. Several of these systems are based on the tumor-node-metastasis (TNM) paradigm or incorporate TNM groupings as a variable [33-35,37]. Other systems, such as the Barcelona-Clinic Liver Cancer (BCLC) staging system, incorporate measures of liver function and underlying disease. Complicating international clinical trial design is the variable use of these systems both within Asia and globally. Each region of Asia represented by the panel currently utilizes a different system. In China, the revised Staging Criteria of Primary Liver Cancer is used. This system was developed by the Chinese Society of Liver Cancer. The system uses criteria based on size, number and location of tumors, lymph node spread, extrahepatic metastasis, portal vein thrombosis, and liver function (Child-Pugh scores) [38]. In Japan, both the staging system and treatment algorithm apply liver function as the first category of evaluation rather than tumor size. Hong Kong does not have a unified staging system. Although BCLC is considered a valuable tool for a treatment algorithm in Hong Kong, the system is considered less useful for prognostication. The Chinese University Prognostic Index (CUPI) [37] has been found useful for prognostication at one center due to the more advanced population [39]. Korea employs a modified International Union Against Cancer (UICC) system and Taiwan uses BCLC.

The TNM-based staging systems have an important drawback: these systems do not account for underlying liver disease [40]. In HCC, the presence of liver disease is a common and important prognostic factor that is integral in determining treatment $[40,41]$. For these reasons, TNM-based systems have limited value in the comprehensive management of HCC. The Child-Pugh (CP) score is a widely-accepted system to evaluate liver function. Despite empirical selection of variables, this tool represents a simple, bedside tool that predicts mortality in cirrhotic patients with a degree of accuracy not substantially less than the more statistically sound model for end-stage liver disease (MELD) [42]. The BCLC staging system incorporates measures of liver function (portal hypertension, bilirubin, and CP scores at higher stages) and has emerged as the standard for clinical trial design [6,43]. However, this system is not generally used in Eastern Asia with the exception of Taiwan. China, specifically, has failed to adopt this system due to the omission of portal vein thrombosis as a factor, which has been shown to independently predict mortality [41]. Additionally, BCLC includes portal venous hypertension which requires an invasive procedure to measure that is not standard practice in Asia. However, the panel indicated that, if required for clinical trials seeking United States Food and Drug Administration approval, BCLC would be acceptable if the protocols also incorporated portal vein hypertension measured and defined with non-invasive standardized methodology - and further evaluation of liver function.

\section{Treatment Practices}

Treatment practices vary somewhat throughout Eastern Asia and no unified treatment algorithm exists. Japan, China, Hong Kong, Korea, and Taiwan each use separate treatment algorithms, all of which differ from the BCLC treatment algorithm $[7,44,45]$. Such variations in treatment practices cause challenges in defining treatment protocols for international clinical trials.

\section{Potentially Curative Treatment Options}

Resection is utilized more often in Eastern Asia versus Western nations, which may reflect diagnosis at earlier stages and less cirrhosis in Asia [46]. In some centres in China, Taiwan, and Japan, between $34-40 \%$ of patients undergo resection, while the proportion is approximately $10-20 \%$ in others. In parts of East Asia [47,48], patients with recurrence undergo re-resection. Local ablation is performed in approximately $15 \%$ of patients in China, Hong Kong, and Taiwan and approximately $30 \%$ of patients in Japan. Liver transplant is the only treatment modality that offers a cure both for HCC and the underlying liver disease, but its application is limited both in Eastern Asia and the West.

\section{Nonsurgical Local Treatments}

Although TACE and transarterial embolization (TAE) are standards of care, significant heterogeneity exists among countries and institutions with respect to the types of embolizing materials and techniques utilized. Embolizing materials used typically include a mixture of iodized oil (lipiodol) and an anthracycline (epirubicin or doxorubicin) or cisplatin followed by gelatin sponge particles (Japan, Taiwan, Hong Kong). Nonetheless, other agents are used, particularly in China where 5-fluorouracil (5-FU) and mitomycin-C may be employed. Japan uses HAI with cisplatin alone, 5-FU and cisplatin (FP), or 5-FU and interferon. Currently, no consensus has been reached regarding the interval between procedures or endpoints. Other local therapies are variably utilized and include intratumoral injection, laser therapy, cryotherapy, microwave coagulation therapy, hepatic arterial infusion (HAI), intraarterial radiotherapy with yttrium-90 and conformal external radiotherapy. 


\section{Systemic Therapy With Sorafenib}

Targeted therapy has been employed only for advanced disease $[7,44,45]$. A multitude of targeted therapies have been investigated for use in HCC; however, only sorafenib is approved for use in Asian and Western countries. These approvals were based on improved survival in the SHARP trial and the parallel Asian phase III trial $[6,49]$. Although sorafenib has been approved in Asia, the agent is not widely used largely due to cost [50]. Costsharing programs have been started in some countries to manage this issue. Such programs have been successful in that they expand usage; however, lack of longterm coverage renders the practice unsustainable.

In addition to cost, emerging evidence suggests that sorafenib may be less well tolerated by Asian patients compared to Western patients. Hand-foot skin reaction (HFSR) appears to be more frequent in Asians, particularly lower-grade reactions. Hand-foot skin reaction (all grades) occurred in $21 \%$ of patients in the US SHARP study; the rate was $45 \%$ in the Asian phase III sorafenib trial $[6,46]$. Grade 3 event rates were $8 \%$ in SHARP compared with $11 \%$ in the Asian trial. Korean and Japanese studies have reported rates of 56\%-57\% (all grades) $[51,52]$. In the Korean population, HFSR was the most common reason for treatment interruption. Indeed, dose reductions for HFSR were more frequent in the Asian phase III trial (11\%) than in SHARP $(5 \%)[6,46]$ The panelists noted that in practice, dose reduction or use of a reduced starting dose of sorafenib is common in Asia. Lower dosing is being investigated in small Asian trials. In a Japanese phase I study, sorafenib $200 \mathrm{mg}$ twice daily led to a $38 \%$ incidence of HFSR [52].

Though HFSR is most common, some differences between Westerners and Asians may be present with respect to the drug's effect on the liver. The Korean population experienced a $4 \%$ rate of grade 3 or 4 hyperbilirubinemia associated with marked ALT elevations [51]. Individual differences in drug metabolism may be present. Increased bilirubin was reported separately in a patient with UGT1A1 polymorphism; the authors proposed that sorafenib inhibition of UGT1A1 in this patient may have contributed to the hyperbilirubinemia [53].

\section{Other Systemic Therapies}

Systemic cytotoxic chemotherapy has failed to prolong survival in advanced HCC [5]. Small studies of cytotoxic chemotherapy plus biochemical modulation may achieve tumor control in patients with good performance status and liver function reserves and no hypersplenism [54-56]. In Korea, chemotherapy is used as part of concurrent chemoradiotherapy protocols at some centers. In Hong Kong, systemic cytotoxic chemotherapy is considered when a patient fails or is ineligible for anti-
VEGF therapy. Chemotherapy was not recommended in Japanese treatment guidelines.

In China, use of traditional Chinese medicine (TCM) is common and unique compared to Western nations. These medicines can be categorized according to two main purposes: 1) promoting liver health and delaying cirrhosis and 2) countering the side effects of chemotherapy. Panelists indicated that the first type of TCM must be allowed in clinical trials; excluding these treatments would severely restrict enrollment. However, the second type of TCM could potentially be excluded if required.

\section{Investigational Targeted Therapy}

Targeted agents are at the forefront of HCC clinical research. Promoting clinical trial participation in Asia is important to foster development of new drugs appropriate for this population. Recently completed phase II trials of new treatments are described below and ongoing phase II and III trials of targeted therapies in HCC are reviewed in Table 1.

The combination of sorafenib and chemotherapy has been investigated in phase II trials. A randomized phase II trial found superior outcomes with the combination of sorafenib plus doxorubicin compared to placebo plus doxorubicin [57]. Median progression-free and overall survival times were 6.9 months and 13.8 months in the sorafenib arm compared to 2.8 months and 6.5 months in the placebo arm, respectively. The combination was associated with a $21 \%$ incidence of left ventricular dysfunction, though mostly of grade 1 or 2 severity. The SECOX trial evaluated sorafenib plus capecitabine and oxaliplatin [58]. Response was observed in 14\% with stable disease in $61 \%$. Median time to progression (TTP) was 7.1 months and median survival was 10.2 months. Toxicities included HFSR, diarrhea, and neutropenia. When sorafenib was paired with metronomic tegafur/ uracil (UFT; $125 \mathrm{mg} / \mathrm{m}^{2}$ twice daily), the combination led to overall response and stable disease rates of $6 \%$ and $51 \%$, respectively [59]. Median progression-free survival was 3.7 months and median survival was 7.4 months. The most common grade 3 or 4 adverse events were fatigue (15\%), HFSR (9\%), and bleeding (8\%).

Sunitinib has been evaluated at various doses and schedules. The SAKK 77/06 trial utilized sunitinib 37.5 $\mathrm{mg}$ /day continuously in 45 Swiss patients [60]. Median progression-free survival (PFS) was 2.8 months and median survival was 9.3 months. The most frequent grade $3 / 4$ toxicities were fatigue in $24 \%$ and thrombocytopenia in $18 \%$. Two US studies evaluated sunitinib 37.5 mg daily for 4 weeks every 6 weeks [61,62]. Response rates were $3 \%-6 \%$ and stable disease rates were $35 \%$ $47 \%$. One study reported PFS and survival; median PFS was 4.0 months and median survival was 9.9 months. 
Table 1 Ongoing Phase II/III Trials in Advanced HCC

\begin{tabular}{|c|c|c|c|c|}
\hline $\begin{array}{l}\text { Study Name } \\
\text { Clinicaltrials.gov } \\
\text { Identifier }\end{array}$ & Phase & Intervention & Setting & Location \\
\hline \multicolumn{5}{|l|}{ Advanced Disease } \\
\hline \multicolumn{5}{|c|}{ Targeted Agents With Cytotoxic Therapy } \\
\hline NCT00832637 & ॥ & Erlotinib + gemcitabine + oxaliplatin & Prior systemic therapy allowed & US \\
\hline $\begin{array}{l}\text { HOG Gl06-101 } \\
\text { NCT00532441 }\end{array}$ & $\|$ & Erlotinib + docetaxel & Third-line or less & US \\
\hline NCT00384800 & $\|$ & Thalidomide + tegafur/uracil & No prior chemotherapy & Taiwan \\
\hline NCT00519688 & $\|$ & Thalidomide + tegafur/uracil & No prior chemotherapy & Taiwan \\
\hline NCT00862082 & $|/| \mid$ & $\begin{array}{l}\text { Sorafenib + PR104 } \\
\text { Sorafenib }\end{array}$ & First-line & US, Asia \\
\hline \multicolumn{5}{|c|}{ Anti-VEGF Agents as Monotherapy } \\
\hline $\begin{array}{l}\text { BRISK } \\
\text { NCT00858871 } \\
\end{array}$ & III & $\begin{array}{l}\text { Brivanib + placebo } \\
\text { Sorafenib + placebo }\end{array}$ & First-line & International \\
\hline NCT00825955 & III & $\begin{array}{l}\text { Brivanib + placebo } \\
\text { BSC + placebo }\end{array}$ & Sorafenib failure & International \\
\hline NCT00699374 & III & $\begin{array}{l}\text { Sunitinib } \\
\text { Sorafenib }\end{array}$ & First-line & International \\
\hline NCT00247676 & ॥ & Sunitinib & First-line & France, Korea, Taiwan \\
\hline \multicolumn{5}{|c|}{ Other Targeted Agents as Monotherapy } \\
\hline NCT00225290 & III & $\begin{array}{l}\text { Thalidomide } \\
\text { Placebo }\end{array}$ & $\begin{array}{l}\text { Any line } \\
\text { Poor liver reserve }\end{array}$ & Taiwan \\
\hline NCT00033462 & $\|$ & Erlotinib & First- or second-line & US \\
\hline NCT00077441 & $\|$ & Bortezomib & First-line & $\begin{array}{l}\text { US, Australia, Korea, } \\
\text { HK }\end{array}$ \\
\hline NCT00390195 & $|/| \mid$ & Everolimus (weekly or daily) & Any line & Taiwan \\
\hline NCT00920192 & $|/| \mid$ & Foretinib & Any line & Taiwan, HK \\
\hline \multicolumn{5}{|c|}{ Combination Targeted Therapy } \\
\hline $\begin{array}{l}\text { SEARCH } \\
\text { NCT00901901 }\end{array}$ & III & Sorafenib + erlotinib Sorafenib & First-line & International \\
\hline NCT00881751 & ॥ & Erlotinib + bevacizumab Sorafenib & First-line & US \\
\hline NCT00365391 & ॥ & Erlotinib + bevacizumab & First- or second-line & US \\
\hline $\begin{array}{l}\text { TCOGP-1209 } \\
\text { NCT00971126 } \\
\end{array}$ & $|/| \mid$ & Thalidomide + sorafenib & First-line & Taiwan \\
\hline NCT00828594 & $|/| \mid$ & $\begin{array}{l}\text { Everolimus + sorafenib Placebo + } \\
\text { sorafenib }\end{array}$ & First-line & International \\
\hline NCT00791544 & $|/| \mid$ & AVE1642* +/- sorafenib or erlotinib & Any line & France \\
\hline \multicolumn{5}{|c|}{ Earlier-stage Disease } \\
\hline $\begin{array}{l}\text { STORM } \\
\text { NCT00692770 }\end{array}$ & III & $\begin{array}{l}\text { Sorafenib } \\
\text { Placebo }\end{array}$ & Adjuvant (post-resection or -local ablation) & International \\
\hline $\begin{array}{l}\text { BRISK-TA } \\
\text { NCT00908752 } \\
\end{array}$ & III & $\begin{array}{l}\text { Brivanib + TACE } \\
\text { Placebo + TACE }\end{array}$ & $B C L C B$ & International \\
\hline NCT00921531 & III & $\begin{array}{l}\text { Thalidomide + TACE } \\
\text { TACE }\end{array}$ & $B C L C A-B$ & China \\
\hline NCT00728078 & $\|/\| / \|$ & Thalidomide, low dose & Adjuvant (post-RFA) & China \\
\hline $\begin{array}{l}\text { START } \\
\text { NCT00990860 } \\
\end{array}$ & $\|$ & Sorafenib + TACE & $B C L C B$ & Taiwan \\
\hline NCT00855218 & $\|$ & $\begin{array}{l}\text { Sorafenib + TACE } \\
\text { Placebo + TACE }\end{array}$ & $B C L C B$ & International \\
\hline $\begin{array}{l}\text { COTSUN } \\
\text { NCT00919009 } \\
\end{array}$ & $\|$ & Sorafenib + TACE & TNM III/IVa & Korea \\
\hline NCT00576199 & $\|$ & Bevacizumab & Pre- and Post-TACE & HK \\
\hline
\end{tabular}


Table 1 Ongoing Phase II/III Trials in Advanced HCC (Continued)

\begin{tabular}{lclll}
\hline JLOG 0901 & I/I & Sorafenib + fluorouracil/platinum HAl & Not suitable for resection, ablation, TACE & Japan \\
NCT00933816 & I/II & Erlotinib + celecoxib & $\begin{array}{l}\text { Adjuvant (post-resection, -TACE, or -RFA), } \\
\text { high-risk }\end{array}$ & US \\
\hline
\end{tabular}

BSC, best supportive care; ECOG, Eastern Cooperative Oncology Group; HAI, hepatic arterial infusion; HK, Hong Kong; HOG, Hoosier Oncology Group; JLOG, Japan Liver Oncology Group; RFA, radiofrequency ablation; TACE, transarterial chemoembolization; US, United States; VEGF, vascular endothelial growth factor

*Anti-insulin-like growth factor receptor-1 monoclonal antibody

The most common grade $3 / 4$ toxicities were fatigue and elevated liver function tests. A study in Europe and Asia that evaluated high-dose sunitinib (50 mg daily for 4 weeks every 6 weeks) found similar response and stable disease rates but higher toxicity with four grade 5 events [63].

Other multiple receptor tyrosine kinase inhibitors that target VEGF under investigation include brivanib, linifanib (formerly ABT-869), vandetanib, and pazopanib. Brivanib inhibits VEGF and fibroblast growth factor; a phase II trial showed median survival of 10 months in treatment-naive patients [64] and a 58\% stable disease rate in patients who failed one prior antiangiogenic therapy [65]. The most frequent grade $3 / 4$ toxicities were hyponatremia (41\%), fatigue (16\%), and AST elevation (19\%) [64]. Linifanib inhibits VEGF and PDGF receptor tyrosine kinases. A phase II study $(\mathrm{n}=44 ; 84 \%$ treatment-naïve) showed a response rate of $7 \%$, median PFS of 3.7 months and median survival of 9.3 months [66]. Toxicities are consistent with anti-VEGF agents. A phase II, placebo-controlled study of vandetanib, which targets VEGFR, EGFR, and RET signaling, showed activity in HCC but failed to meet its primary endpoint of tumor stabilization in a Taiwanese trial [67]. A phase I dose-ranging study of pazopanib, which inhibits VEGF, PDGF, and c-kit, showed evidence of activity [68].

Phase II trials of erlotinib plus bevacizumab are promising. In 16 previously untreated patients, the combination led to a median TTP of 2.3 months and median survival of 13.7 months [69]. In 40 patients, $73 \%$ of whom were previously untreated, the response rate was $25 \%$, median PFS was 9.0 months, and median survival was 15.7 months [70]. In 58 patients, $76 \%$ of whom were previously untreated, median PFS times were 8.8 months in patients with no prior therapy, 7.9 months in patients previously treated with sorafenib, and 6.6 months in those previously treated with therapy other than sorafenib [71]. Corresponding median survival times were 15.6 months, 13.3 months, and 14.4 months. In all studies, adverse events were consistent with the individual drug profiles.

\section{Asian Panel Opinions on Clinical Trial Design}

In 2008, the American Association for the Study of Liver Diseases (AASLD) published a framework for clinical trial design in HCC [7]. During the current expert panel meeting, participants provided their views about clinical trial design from an Asian perspective. These views are outlined in Table 2.

The Asian panel also provided additional insights into clinical trial issues specific to disease stage. The panel noted a great need for trials in resectable disease. The panel felt that testing compounds in the adjuvant setting before establishing efficacy in the metastatic setting is possible, citing positive phase II adjuvant results with muparfostat (formerly PI-88) [72] and noting the need for effective therapies in this setting. The panel also expressed interest in chemoprevention with sorafenib and other agents after resection or local ablation. In unresectable disease, especially where locoregional therapy is indicated, placebo-controlled trials remain feasible, though the panel acknowledged opportunities are limited. In this setting, it may be beneficial to limit enrollment to patients who experience a maximal response after TACE based on modified EASL criteria [73]. Such a requirement would facilitate identification of subsequent disease progression across patients. However, additional research is necessary to identify the best clinical endpoints in this setting. Because it remains difficult to differentiate recurrent disease from a second primary cancer, time to development of a new lesion may be an appropriate outcome in this setting. Finally, in the advanced/metastatic setting, the panel felt that developing new agents in the second-line setting is warranted.

\section{Summary}

Hepatocellular carcinoma is a disease of variable incidence and etiology that is managed differently worldwide. This expert panel has identified key areas that need to be addressed to facilitate clinical trials in Asia. Stratification by viral etiology is desirable within Asia and by region in global trials. Antiviral therapy should also be considered as a stratification factor and incorporated into HCC management in trials. The panel agreed with AASLD that histological diagnosis is not required for trial entry. Staging and treatment plans vary significantly. The panel felt BCLC staging is acceptable for trials as long as portal vein hypertension can be measured and defined with non-invasive standardized 
Table 2 Eastern Asian Panel's Opinions on Clinical Trial Design Aspects

\begin{tabular}{|c|c|}
\hline Design Aspect & Panel Opinion \\
\hline \multicolumn{2}{|l|}{ Patient Population } \\
\hline Diagnosis & - Agree with AASLD recommendations[7] - pathological confirmation OR noninvasive criteria per AASLD guidelines \\
\hline Target population & $\begin{array}{l}\text { - BCLC stage is acceptable, but clinical protocols must account for portal vein involvement and liver function } \\
\text { - Treatment options for CP B/C are needed; CP B/C (ECOG PS } 0 \text { only) is an ideal population to study in advanced/metastatic HCC }\end{array}$ \\
\hline Liver function & $\begin{array}{l}\text { - Agree with AASLD recommendations[7]; however, trials should separately include and/or evaluate patients based on presence } \\
\text { of cirrhosis or liver function grade. }\end{array}$ \\
\hline Stratification & $\begin{array}{l}\text { - Stratification by viral etiology is important in trials conducted within Eastern Asia } \\
\text { - Stratification by use of antivirals should also be considered } \\
\text { - Protocols should standardize antiviral therapy and include appropriate monitoring parameters }\end{array}$ \\
\hline \multicolumn{2}{|l|}{ Treatment } \\
\hline $\begin{array}{l}\text { Control arm for } \\
\text { RCTs }\end{array}$ & $\begin{array}{l}\text { - Heterogeneity in TACE/TAE practices must be addressed } \\
\text { - Placebo-controlled trials are feasible in unresectable disease, especially for those in whom locoregional therapy is indicated, } \\
\text { pending maturity of post-TACE sorafenib data } \\
\text { - AASLD recommendation for sorafenib as comparator in advanced disease [7] is not necessarily reflective of real-world use in } \\
\text { Eastern Asia at this time due to high cost and intolerable side effects }\end{array}$ \\
\hline \multicolumn{2}{|c|}{ Phase-specific Clinical Trial Recommendations } \\
\hline Phase I & $\begin{array}{l}\text { - Consider conducting Asia-specific phase I trials due to the potential for PK/PD differences between Asian and Western } \\
\text { populations; however, Asian phase I trials may not be necessary for all targeted agents } \\
\text { - Population } \\
\text { - CP-A or CP score up to 7-8 (subgroup of CP-B) would be feasible for standard phase I trials } \\
\text { - CP-B with score 8-9 and CP-C could be enrolled in phase I trials testing agents at lower doses }\end{array}$ \\
\hline Phase II & $\begin{array}{l}\text { - For first-line studies in advanced HCC, AASLD recommendation for sorafenib [7] is not necessarily reflective of real-world use in } \\
\text { Eastern Asia at this time due to high cost and intolerable side effects } \\
\text { - Agents demonstrated effective for second-line use in phase II trials (not necessarily phase III trials) can be compared to } \\
\text { sorafenib in first-line studies }\end{array}$ \\
\hline Phase III & $\begin{array}{l}\text { - OS endpoint will soon no longer be appropriate in advanced disease with the introduction of multiple lines of therapies; PFS } \\
\text { may be a surrogate but it is necessary to evaluate correlation with OS (ie, as what was done in colorectal cancer) } \\
\text { - In unresectable disease, the most appropriate endpoint is unknown due to difficulty distinguishing recurrence from second } \\
\text { primary in the liver and unreliability of RECIST; time to development of new lesion is a possible endpoint } \\
\text { - Non-inferiority trials are acceptable if new agents have potential for less toxicity }\end{array}$ \\
\hline
\end{tabular}

AASLD, American Association for the Study of Liver Diseases; BCLC, Barcelona Clinic Liver Cancer; CP, Child-Pugh; OS, overall survival; PFS, progression-free survival; PK/PD - pharmacokinetic/pharmacodynamic; RCT, randomized controlled trial; RECIST, Response Evaluation Criteria in Solid Tumors; TACE/TAE, transarterial chemoembolization/transarterial embolization

methodology and liver disease is further evaluated. Consensus in treatment must be sought to allow multinational trials and it must be recognized that first-line sorafenib is not largely feasible in Asia. Finally, Asian nations must be urged to participate in clinical trials, many of which are ongoing, to advance new treatment options in this challenging disease.

\section{Author details \\ ${ }^{1}$ Prince of Wales Hospital, Shatin, Hong Kong. ${ }^{2}$ National Taiwan University Hospital, Taipei, Taiwan. ${ }^{3}$ Kyorin University Hospital, Tokyo, Japan. ${ }^{4}$ Yonsei University, College of Medicine, Seoul, South Korea. ${ }^{5}$ Samsung Medical Centre, Seoul, South Korea. ${ }^{6} \mathrm{GlaxoSmithKline,} \mathrm{Singapore.}{ }^{7}$ No. 81 Hospital of PLA, Nanjing, China. ${ }^{8}$ Zhongshan Hospital, Shanghai, China.}

\section{Authors' contributions}

All authors contributed equally to the writing of this review. All authors read and approved the final review.

\section{Competing interests}

Junji Furuse has received honoraria from Eli Lilly, Taiho, Bayer, and Eisai, as well as research funding from Taiho. Winnie Yeo has received honoraria from Pfizer, AstraZeneca, Bristol Squibb Meyer, MSD, Roche and GlaxoSmithKline as well as research funding from Novartis. Hanlim Moon and Ee-Min Yeoh are full-time employees of GlaxoSmithkline and hold employee-restricted shares not exceeding GBP 15,000.
Received: 10 June 2010 Accepted: 10 November 2010

Published: 10 November 2010

\section{References}

1. Parkin D, Bray F, Ferlay J, Pisani P: Global cancer statistics, 2002. CA Cancer J Clin 2005, 55:74-108.

2. Kamangar F, Dores GM, Anderson WF: Patterns of cancer incidence, mortality, and prevalence across five continents: defining priorities to reduce cancer disparities in different geographic regions of the world. J Clin Oncol 2006, 24:2137-2150.

3. Kim SR, Kudo M, Hino O, Han KH, Chung YH, Lee HS, for the Organizing Committee of the Japan-Korea Liver Symposium (JKLS): Epidemiology of hepatocellular carcinoma in Japan and Korea. Oncology 2008, 75(Suppl 1):13-16.

4. Donato F, Boffetta P, Puoti M: A meta-analysis of epidemiological studies on the combined effect of hepatitis $B$ and $C$ virus infections in causing hepatocellular carcinoma. Int J Cancer 1998, 75:347-354.

5. Mathurin $P$, Rixe $O$, Carbonell $N$, et al: Review article: overview of medical treatments in unresectable hepatocellular carcinoma - an impossible meta-analysis? Aliment Pharmacol Ther 1998, 12:111-126.

6. Llovet JM, Ricci S, Mazzaferro V, for the SHARP Investigators Study Group, et al: Sorafenib in advanced hepatocellular carcinoma. N Engl J Med 2008, 359:378-390.

7. Llovet JM, Di Bisceglie AM, Bruix J, Panel of Experts in HCC-Design Clinical Trials, et al: Design and endpoints of clinical trials in hepatocellular carcinoma. J Natl Cancer Inst 2008, 100:698-711.

8. El-Serag HB, Mason AC: Rising incidence of hepatocellular carcinoma in the United States. N Engl J Med 1999, 340:745-750. 
9. Everhart JE: Viral hepatitis. The burden of digestive diseases in the United States.Edited by: Everhart JE. Washington, DC: US Department of Health and Human Services, Public Health Service, National Institutes of Health, National Institute of Diabetes and Digestive and Kidney Diseases: US Government Printing Office, 2008: NIH Publication No. 09-6443; [http://www3.niddk.nih.gov/Burden_of_Digestive_Diseases/index. shtml\#TOC], Accessed November 13, 2009.

10. Raza SA, Clifford GM, Franceschi S: Worldwide variation in the relative importance of hepatitis $B$ and hepatitis $C$ viruses in hepatocellular carcinoma: a systematic review. Br J Cancer 2007, 96:1127-1134.

11. Yuen MF, Hou JL, Chutaputti A; Asia Pacific Working Party on Prevention of Hepatocellular Carcinoma: Hepatocellular carcinoma in the Asia pacific region. J Gastroenterol Hepatol 2009, 24:346-353.

12. Beasley R, Hwang L-Y, Lin C-C, et al: Hepatocellular carcinoma and hepatitis B virus: a prospecitve study of 22707 men in Taiwan. Lancet 1981, 2:1129-1133.

13. Hsu C, Shen YC, Cheng CC, et al: Geographic difference in survival outcome for advanced hepatocellular carcinoma: Implications on future clinical trial design. Contemp Clin Trials 2009.

14. Pawlik TM, Poon RT, Abdalla EK, et al: Hepatitis serology predicts tumor and liver-disease characteristics but not prognosis after resection of hepatocellular carcinoma. J Gastrointest Surg 2004, 8:794-805.

15. Chen C-H, Huanga G-T, Yanga P-M, et al: Hepatitis B- and C-related hepatocellular carcinomas yield different clinical features and prognosis. Eur J Cancer 2006, 42:2524-2529.

16. Cantarini MC, Trevisani F, Morselli-Labate AM, et al: Effect of the etiology of viral cirrhosis on the survival of patients with hepatocellular carcinoma. Am J Gastroenterol 2006, 101:91-98.

17. Jang JW, Choi JY, Bae SH, et al: Transarterial chemo-lipiodolization can reactivate hepatitis $B$ virus replication in patients with hepatocellular carcinoma. J Hepatol 2004, 41:427-435.

18. Yeo W, Lam KC, Zee B, et al: Hepatitis B reactivation in patients with hepatocellular carcinoma undergoing systemic chemotherapy. Ann Oncol 2004, 15:1661-1666.

19. Yeo W, Chan PK, Ho WM, et al: Lamivudine for the prevention of hepatitis B virus reactivation in hepatitis B s-antigen seropositive cancer patients undergoing cytotoxic chemotherapy. J Clin Oncol 2004, 22:927-934.

20. Martyak LA, Taqavi E, Saab S: Lamivudine prophylaxis is effective in reducing hepatitis $B$ reactivation and reactivation-related mortality in chemotherapy patients: a meta-analysis. Liver Int 2008, 28:28-38.

21. Loomba R, Rowley A, Wesley R, Liang TJ, Hoofnagle JH, Pucino F, Csako G: Systematic review: the effect of preventive lamivudine on hepatitis B reactivation during chemotherapy. Ann Intern Med 2008, 148:519-528.

22. Jang JW, Choi JY, Bae SH, et al: A randomized controlled study of preemptive lamivudine in patients receiving transarterial chemolipiodolization. Hepatology 2006, 43:233-240.

23. Li N, Lai EC, Shi J, et al: A comparative study of antiviral therapy after resection of hepatocellular carcinoma in the immune-active phase of hepatitis B virus infection. Ann Surg Oncol 2009

24. Kuzuya $T$, Katano $Y$, Kumada $T$, et al: Efficacy of antiviral therapy with lamivudine after initial treatment for hepatitis B virus-related hepatocellular carcinoma. J Gastroenterol Hepatol 2007, 22:1929-1935.

25. Koda M, Nagahara T, Matono T, et al: Nucleotide analogs for patients with HBV-related hepatocellular carcinoma increase the survival rate through improved liver function. Intern Med 2009, 48:11-17.

26. Breitenstein S, Dimitroulis D, Petrowsky $\mathrm{H}$, et al: Systematic review and meta-analysis of interferon after curative treatment of hepatocellular carcinoma in patients with viral hepatitis. Br J Surg 2009, 96:975-981.

27. Shen YC, Hsu C, Chen LT, et al: Adjuvant interferon therapy after curative therapy for hepatocellular carcinoma (HCC): a meta-regression approach. J Hepatol 2010.

28. Altekruse SF, McGlynn KA, Reichman ME: Hepatocellular carcinoma incidence, mortality, and survival trends in the United States from 1975 to 2005. $J$ Clin Oncol 2009, 27:1485-1491.

29. Ikai I, Arii S, Ichida T, et al: Report of the 16th follow-up survey of primary liver cancer. Hepatol Res 2005, 32:163-172.

30. Ferrante JM, Winston DG, Chen P-H, de la Torre AN: Family physicians' knowledge and screening of chronic hepatitis and liver cancer. Fam Med 2008, 40:345-351.
31. Chalasani N, Said A, Ness R, et al: Screening for hepatocellular carcinoma in patients with cirrhosis in the United States: results of a national survey. Am J Gastroenterol 1999, 94:2224-222.

32. Davila JA, Weston A, Smalley W, El-Serag HB: Utilization of screening for hepatocellular carcinoma in the United States. J Clin Gastroenterol 2007, 41:777-782.

33. Ueno S, Tanabe G, Nuruki K, Hamanoue M, Komorizono Y, Oketani M, Hokotate H, Inoue H, Baba Y, Imamura Y, Aikou T: Prognostic performance of the new classification of primary liver cancer of Japan (4th edition) for patients with hepatocellular carcinoma: a validation analysis. Hepatol Res 2002, 24:395-403.

34. National Comprehensive Cancer Network: NCCN Clinical practice guidelines in oncology: hepatobiliary cancers v.2.2009. [http://www.ncen. org], Accessed September 25, 2009.

35. Kee K-M, Wang J-H, Lee C-M, et al: Validation of clinical AJCC/UICC TNM staging system for hepatocellular carcinoma: analysis of 5,613 cases from a medical center in southern Taiwan. Int I Cancer 2007, 120:2650-2655.

36. Marrero JA, Fontana RJ, Barrat A, et al: Prognosis of hepatocellular carcinoma: comparison of 7 staging systems in an american cohort. Hepatol 2005, 41:707-716.

37. Leung TW, Tang AM, Zee B, Lau WY, Lai PB, Leung KL, Lau JT, Yu SC, Johnson PJ: Construction of the Chinese University Prognostic Index for hepatocellular carcinoma and comparison with the TNM staging system, the Okuda staging system, and the Cancer of the Liver Italian Program staging system: a study based on 926 patients. Cancer 2002, 94:1760-1769.

38. Chinese Society of Liver Cancer: The criteria of clinical diagnosis and staging of primary liver cancer. Chin J Hepatol 2001, 12:324.

39. Yeo W, Liem TG, Chan SL, et al: Prognostic system for hepatitis B virus (HBV)-related hepatocellular carcinoma- prospective validation of the Chinese University Prognostic Index Abstr. J Clin Oncol 2008, 26(May 20 suppl):4591

40. O'Neil BH, Venook AP: Hepatocellular carcinoma: the role of the North American GI Steering Committee Hepatobiliary Task Force and the advent of effective drug therapy. The Oncologist 2007. 12:1425-1432.

41. Tandon P, Garcia-Tsao G: Prognostic indicators in hepatocellular carcinoma: a systematic review of 72 studies. Liver Int 2009, 29:502-510.

42. Boursier J, Cesbron E, Tropet A-L, Pilette C: Comparison and improvement of MELD and Child-Pugh score accuracies for the prediction of 6-month mortality in cirrhotic patients. J Clin Gastroenterol 2009, 43:580-585.

43. Lu W, Dong J, Huang Z, Guo D, Liu Y, Shi S: Comparison of four current staging systems for Chinese patients with hepatocellular carcinoma undergoing curative resection: Okuda, CLIP, TNM and CUPI. $J$ Gastroenterol Hepatol 2008, 23:1874-1878.

44. Clinical practice guidelines for hepatocellular carcinoma 2005 version 1.0. Japanese Society of Hepatology. [http://www.jsh.or.jp/english/08Treatment_algorithm.pdf], Updated 2005, Accessed December 6, 2009.

45. Korean Liver Cancer Study Group and National Cancer Center: Practice guidelines for management of hepatocellular carcinoma 2009. Korean J Hepatol 2009, 15:391-423.

46. Bruix J, Sherman M: Management of hepatocellular carcinoma. Hepatol 2005, 42:1208-123

47. Sugimachi K, Maehara S, Tanaka S, Shimada M: Repeat hepatectomy is the most useful treatment for recurrent hepatocellular carcinoma. $J$ Hepatobiliary Pancreat Surg 2001, 8:410-416.

48. Jeng KS, Yang FS, Chiang HJ, Ohta I: Repeat operation for nodular recurrent hepatocellular carcinoma within the cirrhotic liver remnant: a comparison with transcatheter arterial chemoembolization. World I Surg 1992, 16:1188-1191.

49. Cheng AL, Kang YK, Chen Z, et al: Efficacy and safety of sorafenib in patients in the Asia-Pacific region with advanced hepatocellular carcinoma: a phase III randomised, double-blind, placebo-controlled trial. Lancet Oncol 2009, 10:25-34.

50. Poon D, Anderson BO, Chen L-T, et al: Management of hepatocellular carcinoma in Asia: consensus statement from the Asian Oncology Summit 2009. Lancet Oncol 2009, 10:1111-1118

51. Lee HC: Systemic chemotherapy of hepatocellular carcinoma - Korean experience. Oncology 2008, 75:114-118.

52. Furuse J, Ishii $\mathrm{H}$, Nakachi $\mathrm{K}$, et al: Phase I study of sorafenib in Japanese patients with hepatocellular carcinoma. Cancer Sci 2008, 99:159-165. 
53. Meza-Junco J, Chu QS, Christensen O, Rajagopalan P, Das S, Stefanyschyn R, Sawyer MB: UGT1A1 polymorphism and hyperbilirubinemia in a patient who received sorafenib. Cancer Chemother Pharmacol 2009, 65:1-4.

54. Cheng AL, Chen YC, Yeh KH, et al: Chronic oral etoposide and tamoxifen in the treatment of far-advanced hepatocellular carcinoma. Cancer 1996 77:872-877.

55. Cheng AL, Yeh KH, Fine RL, et al: Biochemical modulation of doxorubicin by high-dose tamoxifen in the treatment of advanced hepatocellular carcinoma. Hepatogastroenterology 1998, 45:1955-1960.

56. Lu YS, Hsu C, Li CC, et al: Phase II study of combination doxorubicin, interferon-alpha, and high-dose tamoxifen treatment for advanced hepatocellular carcinoma. Hepatogastroenterology 2004, 51:815-819.

57. Abou-Alfa GK, Johnson P, Knox J, et al: Final results from a phase II (PhII), randomized, double-blind study of sorafenib plus doxorubicin (S+D) versus placebo plus doxorubicin $(P+D)$ in patients (pts) with advanced hepatocellular carcinoma (AHCC). American Society of Clinical Oncology Gastrointestinal Cancers Symposium; 2008, Abstr 128

58. Yau T, Chan P, Cheung FY, et al: Phase II trial of sorafenib with capecitabine and oxaliplatin (SECOX) in patients with locally advanced or metastatic hepatocellular carcinoma. Eur J Cancer Supp/ 2009, 7:20.

59. Shen $\mathrm{YC}, \mathrm{Hsu} \mathrm{CH}, \mathrm{Hsu}$ C, et al: A phase II study of sorafenib in combination with tegafur/uracil (UFT) for Asian patients with advanced hepatocellular carcinoma (HCC). J Clin Oncol Abstr 2009, 27(suppl), Abstr 4589.

60. Koeberle D, Montemurro M, Samaras $\mathrm{P}$, et al: Continuous sunitinib treatment in patients with unresectable hepatocellular carcinoma (HCC): a multicenter phase II trial (SAKK 77/06 and SASL 23). J Clin Oncol Abstr 2009, 27(suppl), Abstr 4591.

61. Hoda D, Catherine C, Strosberg J, et al: Phase II study of sunitinib malate in adult pts (pts) with metastatic or surgically unresectable hepatocellular carcinoma (HCC). American Society of Clinical Oncology Gastrointestinal Cancers Symposium; 2008, Abstr 267.

62. Zhu AX, Sahani DV, di Tomaso E, et al: Sunitinib monotherapy in patients with advanced hepatocellular carcinoma (HCC): Insights from a multidisciplinary phase II study. J Clin Oncol Abstr 2008, 26(May 20 suppl), Abstr 452

63. Faivre S, Raymond E, Boucher E, Douillard J, Lim HY, Kim JS, et al: Safety and efficacy of sunitinib in patients with advanced hepatocellular carcinoma: an open-label, multicentre, phase II study. Lancet Oncol 2009, 10:794-800.

64. Rauol JL, Finn RS, Kang YK, et al: An open-label phase II study of first- and second-line treatment with brivanib in patients with hepatocellular carcinoma (HCC). J Clin Oncol Abstr 2009, 27(suppl), Abstr 4577.

65. Finn RS, Kang Y, Park J, Harris R, Donica M, Walters I: Phase II, open label study of brivanib alaninate in patients (pts) with hepatocellular carcinoma (HCC) who failed prior antiangiogenic therapy. American Society of Clinical Oncology Gastrointestinal Cancers Symposium; 2009, Abstr 200

66. Toh HC, Chen P, Knox JJ, et al: International phase 2 trial of ABT-869 in patients with advanced hepatocellular carcinoma (HCC). Eur J Cancer Suppl 2009, 7:366, Abstr PD-6517.

67. Hsu C, Yang TS, Huo TL, et al: Evaluation of vandetanib in patients with inoperable hepatocellular carcinoma (HCC): a randomized, double-blind, parallel group, multicentre, phase II study. Joint ECCO 15 - 34TH ESMO Multidisciplinary Congress 2009 [http://ex2.excerptamedica.com/CIW-09ecco/ index.cfm?fuseaction=CIS2002\&hoofdnav=Abstracts\&content=abs details\&what $=$ AUTHOR\&searchtext $=$ hsu\&topicselected $=*$ \&selection $=$ ABSTRACT\&aryStartRowDetail = 7], Abstract No: PD-6518. Accessed November 2, 2009

68. Yau CC, Chen PJ, Curtis M, et al: A phase I study of pazopanib in patients with advanced hepatocellular carcinoma. J Clin Oncol Abstr 2009, 27(suppl), Abstr 3561.

69. Govindarajan R, Siegel ER, Makhoul I, et al: Phase II study of efficacy of bevacizumab and erlotinib in inoperable previously untreated hepatocellular carcinoma (HCC). American Society of Clinical Oncology Gastrointestianl Cancers Symposium; 2009, Abstr 264

70. Thomas MB, Morris JS, Chadha R, et al: Phase II trial of the combination of bevacizumab and erlotinib in patients who have advanced hepatocellular carcinoma. J Clin Oncol 2009, 27:843-850.
71. Kaseb $A O$, Iwasaki MM, Javle $M$, et al: Biological activity of bevacizumab and erlotinib in patients with advanced hepatocellular carcinoma (HCC). J Clin Oncol Abstr 2009, 27(suppl), Abstr 4522.

72. Liu CJ, Lee PH, Lin DY, et al: Heparanase inhibitor PI-88 as adjuvant therapy for hepatocellular carcinoma after curative resection: a randomized phase II trial for safety and optimal dosage. J Hepatol 2009, 50:958-968.

73. Bruix J, Sherman M, Llovet JM, et al: Clinical management of hepatocellular carcinoma. Conclusions of the Barcelona-2000 EASL conference. European Association for the Study of the Liver. J Hepatol 2001, 35:42

\section{Pre-publication history}

The pre-publication history for this paper can be accessed here: http://www.biomedcentral.com/1471-2407/10/620/prepub

doi:10.1186/1471-2407-10-620

Cite this article as: Yeo et al:: Eastern asian expert panel opinion: designing clinical trials of molecular targeted therapy for hepatocellular carcinoma. BMC Cancer 2010 10:620.

\section{Submit your next manuscript to BioMed Central and take full advantage of:}

- Convenient online submission

- Thorough peer review

- No space constraints or color figure charges

- Immediate publication on acceptance

- Inclusion in PubMed, CAS, Scopus and Google Scholar

- Research which is freely available for redistribution

Submit your manuscript at www.biomedcentral.com/submit
Ciomed Central 